\title{
A SAM-Based Analysis of the Economic Impact of Frauds in the Italian Wine Value Chain
}

\author{
Donato Romano ${ }^{1}$ (D) Benedetto Rocchi ${ }^{1}$ - Ahmad Sadiddin ${ }^{2}$. \\ Gianluca Stefani $^{1}$ - Raffaella Zucaro ${ }^{3}$ - Veronica Manganiello ${ }^{3}$
}

Received: 22 September 2019 / Accepted: 18 November 2020 / Published online: 7 February 2021

(c) The Author(s) 2021

\begin{abstract}
The objective of this paper is twofold: firstly, it analyzes the evolution of frauds in the Italian wine value chain over the period 2007-2015, and then, using a properly disaggregated social accounting matrix (SAM) of the Italian economy, it simulates the impact of wine frauds on the national economy in terms of growth, employment, value added and income. The wine industry is the sector most exposed to frauds within the Italian agro-food system accounting for $88 \%$ of total value of seized agrofood outputs. Most irregularities (95\%) are made by only three agents, specifically individual wineries, bottlers-wholesalers and retailers. We estimated industry-specific SAM multipliers to assess the share of the Italian economy depending on irregular wine production. These activities account for $11.5 \%$ of specialized permanent crop farms output and over $25 \%$ of wine industry output. This is a sign of vulnerability of the wine industry: should a food scandal/scare determine a drop in consumers' demand, the negative effect on production activities of these sectors may be large. The SAM was also used to perform an impact analysis adopting a counterfactual approach. Results show a slightly positive increase of value added (6 million euro) along with an overall decrease in the activity level (an output loss of 406 million euro and more than six thousand full time jobs lost). This contractionary effect can be explained with fraud rents. Indeed, the extra-profits from frauds do not activate the economy circular flow as most of them leak out to exogenous accounts such as the public administration and the rest of the world.
\end{abstract}

Keywords Food frauds $\cdot$ Wine $\cdot$ Social accounting matrix $\cdot$ Italy

JEL Classification E16: Social Accounting Matrix - E17: Forecasting and Simulation: Models and Applications - L66: Food; Beverages; Cosmetics; Tobacco; Wine and Spirits - Q13: Agricultural Markets and Marketing; Cooperatives; Agribusiness . Q18: Agricultural Policy; Food Policy

Extended author information available on the last page of the article 


\section{Introduction}

The Italian agri-food system is one of the most important components of the "Made in Italy". In 2018, the agricultural sector produced outputs valued 55.9 billion euro, employing 1.2 million labor units and exporting some 6.8 billion euro of agricultural goods (ISTAT 2019a, b; ISMEA 2019a), while the food industry turnover peaked at 140 billion euro, with 385 thousand employees and export exceeding 35.1 billion euro, which ranks food as the second Italian largest exporting sector in 2018 (ISMEA 2019a; Federalimentare 2019a). In Italy the wine sector is the third most important agri-food sector after dairy and meat in terms of production with an industrial turnover exceeding 13.2 billion euro and more than 13 thousand employees in the wine industry, but it is the most important agri-food exporting sector accounting for 6.2 billion euro in 2018 , i.e. $14.8 \%$ of total agri-food export, mostly represented by high-quality wines with geographical indication (ISMEA 2019b). ${ }^{1}$ In fact, Italy ranks first at world level in terms of number of geographically denominated wines, with 408 Protected Designation of Origin (DOP) and 118 Protected Geographical Indications (IGP) wines (FEDERDOC 2019), ${ }^{2}$ accounting for $58.2 \%$ of wine production and for an astonishing $88.2 \%$ of wine export in 2018 .

The large share of high-quality wine produced by the Italian wine industry, the increasing reputation of Italian wines on domestic and foreign markets that fetch significant price premiums, and the large number of small production units contribute to create significant opportunities for fraud - that is "an intentional illegal act made for sake of economic gain" (Spink and Moyer 2011) ${ }^{3}$ —in the wine industry. In fact, wine ranks first by far among agri-food value chains in terms of number of detected irregularities and value of seized products (ICQRF 2019). However, though food frauds have recently drawn considerable attention because of the growing risk of food fraud (Avery 2014), ${ }^{4}$ frauds in the wine value chain is a neglected topic. Besides the yearly reports of inspection bodies, which disseminate information about monitoring activities, the literature on the topic is scanty (INEA 2011; Menghini and Fabbri 2013). Importantly, there is a fundamental gap in the economic literature in so far no comprehensive analysis of frauds in the wine sector in Italy has been carried out so far and specifically no quantitative assessment of the economic impact of wine frauds on the Italian economy.

\footnotetext{
1 Italy is one of the top players of the wine sector at world level ranking first in terms of production, second in terms of export (both in volume and value) and third in terms of consumption (ISMEA 2019b).

2 The Legislative Decree n. 61/2010 unified the classification of all food products that have designation of origin, including wines, into two major categories, namely: the DOP (Protected Designation of Origin) products, which includes the existing wine's DOC (Controlled Designation of Origin) and DOCG (Guaranteed and Controlled Designation of Origin), and the IGP (Protected Geographical Indication), which also includes the already existing IGT (Typical Geographical Indication).

3 In mere descriptive terms, food frauds encompass alteration, adulteration, sophistication, and falsification of agri-food products including the falsification of their trademarks (i.e., counterfeiting). However, in this paper we adopt the definition above, which emphasizes the intentionality of the action done for the sake of economic gain, and may or may not cause harm (Spink et al. 2013; Manning and Soon 2016).

4 This is true for Italy as well, where the agri-food sector is the third most affected sector by counterfeiting after clothing and audio-visual, CD \& DVD (CENSIS 2012).
} 
The overall objective of this paper is to shed light on the phenomenon of frauds in the wine sector adopting a value chain perspective, that is analyzing grape production as well as wine-making and distribution up to final consumption. This will be done using as primary source the data on inspection activities carried out by the Central Inspectorate for Agri-food Quality Protection and Fraud Repression (Ispettorato Centrale per la Qualità e la Repressione delle Frodi, ICQRF) of the Italian Ministry of Agriculture (MIPAAF). Specifically, we will (i) analyze the evolution of the fraud in the wine value chain over the period 2007-2015, (ii) provide some insights on how the phenomenon is distributed by geographical location and value chain stages, and (iii) assess the economic importance of frauds, estimating how large is the irregular economy linked to fraudulent activities in the wine value chain and what is its impact on the Italian economy in terms of output, value added, employment and household income. The impact analysis will be pursued building a properly disaggregated social accounting matrix (SAM) of the Italian economy to simulate the effect of fraudulent activities perpetrated by the operators along the wine value chain. In fact, the database provided by ICQRF refers only to fraudulent activities carried out within the country. Because of this lack of data, fraudulent activities such as the import of counterfeited agri-food products or the so-called "Italian sounding" are not accounted for in the analysis. $^{5}$

The paper is organized as follows. Section 2 briefly describes how the wine value chain is structured in Italy. Section 3 summarizes the most common frauds in the wine value chain. Section 4 briefly recalls what is a SAM and proposes a methodology to carry out an impact evaluation of food frauds in a SAM counterfactual framework. Section 5 explains how the SAM of the Italian economy and the vector of wine fraud shocks has been built. Section 6 discusses the results of the empirical analysis. Section 7 concludes.

\section{The Italian Wine Value Chain}

The Italian wine value chain is made by a complex cobweb of material and financial flows connecting vineyards to final consumption. Leaving aside the exchange with foreign markets, involving import of bulk wines accounting for no more than $5 \%$ of total domestic wine availability and export of bulk and bottled wine accounting for $42 \%$ of total domestic wine production (ISMEA 2019b), the wine value chain can be broken down into four main stages (Fig. 1) that are: the production of raw material (grape producing farms), wine-making (wineries), packaging and logistics (bottling, transport, storage firms) and distribution to final consumers, represented by channels as different as the large modern distribution, retailers and the hotel-restaurants and catering (Ho.Re.Ca.) channel. Besides the agents involved in production, processing,

\footnotetext{
5 Italian sounding is a phenomenon encompassing the commercialization abroad of food products packaged using labels, symbols, pictures, etc. that resemble originally produced Italian goods. Although an accurate assessment of this phenomenon is yet to come, rough estimates show that the value of Italian sounding products is as high as 90 billion euro in 2018, that is $64 \%$ of the legal food industry turnover (Federalimentare 2019 b). However, it is likely that the impact of the Italian sounding on a product such wine is less important than for other food products such as cheese and olive oil (Federalimentare 2016).
} 


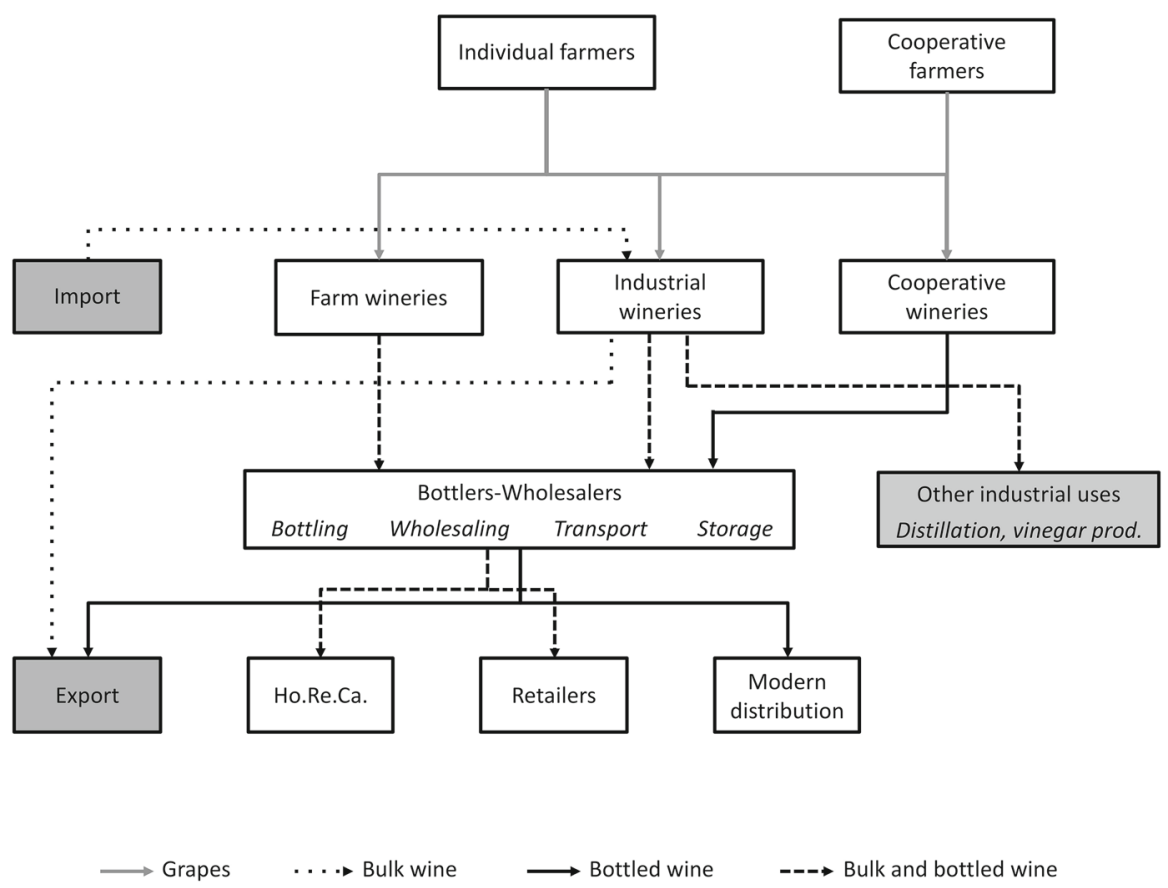

Fig. 1 Structure of the Italian wine value chain. Source: elaboration based on Malorgio et al. (2011) and ISMEA (2019b)

packaging and distribution, there are other categories of agents involved in services associated with production, such as nurseries, wine yeast producers, oenotechnics, and marketing such as exporters, importers, certification agencies, communication agencies, who play an increasingly important role.

In terms of fraud risk the most important stages are the first three, i.e. grape production, processing, and packaging. The three most important operators in these stages are grape producers, wine-makers and bottlers. According to the latest available data (Malorgio et al. 2011; Mazzarino and Corsi 2014; MIPAAF 2017; ISMEA 2019b), these three categories total around 320 thousand operators (Table 1). The vast majority of them (310 thousands) are grape producers who can in turn be broken down into individual farmers, representing 54\% of total farmers involved in the value chain and accounting for $52 \%$ of the grapes produced in Italy, and farmers who are members of a wine-making cooperative, accounting for $46 \%$ of total grape producers and contributing with a share of $48 \%$ to total domestic production of grapes for wine-making (Mazzarino and Corsi 2014). The grape supply is highly fragmented, with a myriad of small farms averaging only 2.1 hectare each (ISMEA 2019b). Only farms whose owners are cooperative members feature some aggregation of their individual supply 
Table 1 Major actors in the Italian wine value chain, 2018

\begin{tabular}{|c|c|c|c|}
\hline Actors & & Number & Share of output $(\%)$ \\
\hline \multirow[t]{3}{*}{ Farmers (grape producers) } & Individual farmers & 168,719 & 52 \\
\hline & Cooperative members ${ }^{\mathrm{a}}$ & 141,709 & 48 \\
\hline & Total farmers & 310,428 & 100 \\
\hline \multirow[t]{4}{*}{ Wineries (processing) } & Farm wineries ${ }^{\mathrm{b}}$ & 42,000 & 21 \\
\hline & Industrial wineries & 1807 & 29 \\
\hline & Cooperative wineries & 518 & 50 \\
\hline & Total wineries & 44,325 & 100 \\
\hline \multirow[t]{3}{*}{ Bottlers (packaging) } & Pure bottlers & 1600 & 20 \\
\hline & Integrated bottlers & 6400 & 80 \\
\hline & Total bottlers & 8000 & 100 \\
\hline Grand total $^{\mathrm{c}}$ & & 320,753 & \\
\hline
\end{tabular}

Source: elaboration on data from Malorgio et al. (2011), Mazzarino and Corsi (2014), MIPAAF (2017) and ISMEA (2019b)

a 2016 data

$\mathrm{b}_{2017}$ data

${ }^{\mathrm{c}}$ The grand total accounts for 42,000 farmers who are also wine-makers

providing their whole production to the coop winery they belong to. ${ }^{6}$ However, also in this case, the farming size is generally small (MIPAAF 2017).

The processing phase accounts for 44 thousand wineries. Most of them (42 thousand) are small farm wineries accounting for one fifth of total domestic wine production. Usually farm wineries are integrated with grape farms that process their own grapes, supplemented sometimes with purchased grapes. In order to be economically viable, many small wineries integrate functions other than wine-making such as direct sale. Similarly, rather than bottling their own wine, these small wineries usually resort to mobile and/or fixed bottling plants, which quite frequently can also provide trading services (mostly at wholesale stage). An important segment of the processing stage is represented by coop wineries. These wineries process the grapes provided by cooperative members but may also integrate their own provision of raw material by purchasing grapes from individual farmers through the spot market. Although coop wineries total only 518 cooperatives, they account for one half of total domestic wine production. The remaining share of domestic wine production $(29 \%)$ is produced by industrial wineries.

Packaging is the most concentrated stage within the value chain, primarily because of the costly investment required to establish bottling lines. Bottlers account for roughly 8000 operators, made almost exclusively by industrial and cooperative wineries, plus a small proportion of farm wineries (Malorgio et al. 2011), that integrate wine-making with bottling. Bottling operators are quite heterogeneous in terms of vertical integration along the wine value chain: roughly one fifth of them being purely

\footnotetext{
6 Two coop farms out of three are contractually committed to provide their own whole grape crop to the coop processing plant, and a non-trivial share of cooperatives (23\%) regulates their raw material provision according to provision plans the coop farmers have to comply with (MIPAAF 2017).
} 


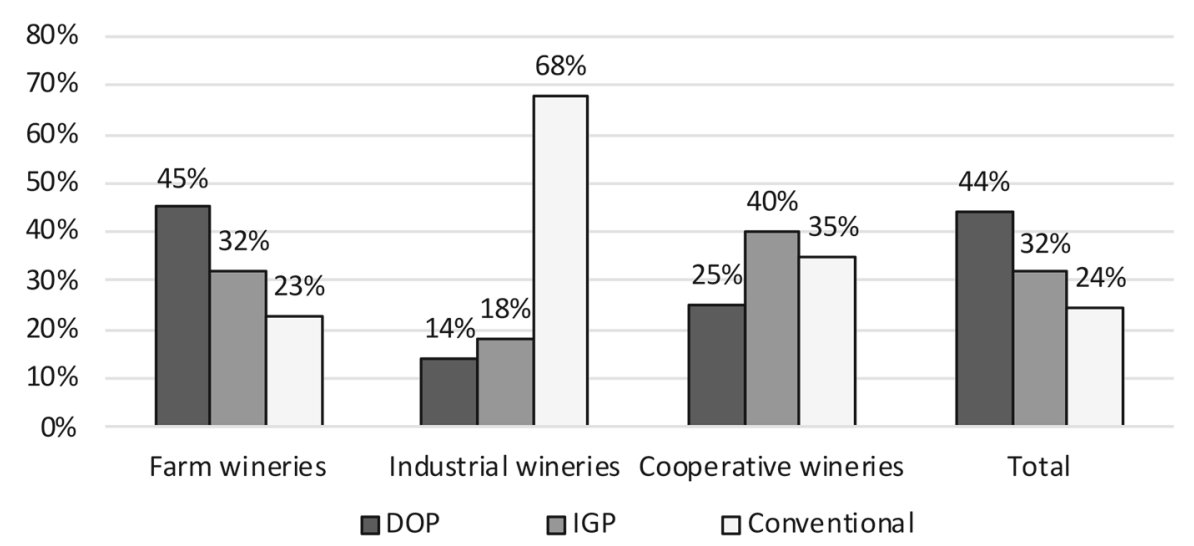

Fig. 2 Wineries' orientation in terms of product quality characteristics. Source: elaboration on data from Malorgio et al. (2011)

bottlers, while the rest integrating functions other than bottling, such as grape processing into wine. According to Mazzarino and Corsi (2014), bottlers are increasingly providing also wholesale services. The bottlers-wholesalers perform a double function: from one hand, they connect wine producers to the stage of final distribution; on the other hand, they are responsible of transportation and/or storage of wine sometimes going downstream up to final sale, which may include also exports.

From the structural viewpoint, the Italian wine value chain is characterized by high fragmentation of involved farms/firms. At the same time the value chain is increasingly concentrated moving from production to processing and packaging. In terms of conduct, the wine-making units, whether integrated or not, show different orientation in terms of quality characteristics of their output (Fig. 2). Farm and cooperative wineries are more specialized in high-quality wines such as DOP and IGP wines, while most of industrial wineries $(68 \%)$ produce only conventional wine.

\section{Frauds in the Italian Wine Value Chain}

\subsection{Types of Frauds}

Although food fraud is a hot topic in politically debates and news headlines, frauds in the Italian wine value chain have not attracted the scholarly interest so far. To the best of our knowledge, there are only a couple of studies dealing with this issue. INEA (2011) published a report analyzing the wine, olive oil and dairy value chains in order to support ICQRF activity planning. However, the report relies only on a qualitative analysis of secondary data and expert judgments to draw some suggestions on how ICQRF monitoring activities could be improved. Menghini and Fabbri (2013) edited a report on the traceability in the wine value chain that analyzes the organization of monitoring activities in the value chain. However, this study is mostly a discussion of current practices rather than a comprehensive analysis of the issues at stake. It 
emphasizes the key role of the inspection systems for the wellbeing of consumers as well as producers (Iaderosa 2013) and the need to protect primarily DOP and IGP wines (Fabbri 2013; Rosellini and Fabbri 2013).

Experts and operators within the value chain acknowledge that frauds are pervasive, highly differentiated and perpetrated at different stages of the value chain. Indeed, over the last decades several factors have contributed to expand the determinants of the socalled "fraud triangle" model originally proposed by Cressey (1953), ${ }^{7}$ thus providing increased room for fraudulent activities. We refer to factors as diverse as the increased competition in domestic and world markets, the increased complexity of globalized value chains, the high level of sophistication of many production processes, and the global recession and its aftermaths. As a result, the share of irregular product and the value of seizures in the wine value chain have been increasing over the last years (Rocchi et al. 2020).

Both experts and statistical evidence show that the most important frauds in the value chain involve (i) sophistication such as sugar/alcohol addition, flavoring, use of wine processing by-products such as the wine dregs, use of grapes other than the grapes declared in the label, etc., and (ii) partial or total falsification of DOP and IGP wines through not-compliance with production codes, incorrect DOP/IGP labeling, incorrect administrative rules on process documentation and quality certification, etc. (ICQRF 2019). While the first group includes practices that can be potentially harmful to human health, the second category is generally much less harmful but has generally greater economic impact (INEA 2011). In terms of agents of frauds, the first category is generally confined to the agents involved in the processing phase (i.e. wine-makers), while the second category is spread throughout the value chain. Since the opportunity to make fraud depends on the level of commercialization of the relevant agents, it is likely that the second group of frauds is more concentrated with agents that perform bottling and distribution of wines, especially exporting firms, to take the highest advantage from the reputation of Italian wines abroad (De Franceschi 2016). Actually, most frauds in the wine supply chain are a combination of these two forms of fraudulent behavior.

\subsection{Irregularities and Seizures Along the Value Chain}

For the purpose of the analysis to be carried out in this study, a food fraud exists whenever an ICQRF inspected product features any kind of irregularity no matter if it leads to the product seizure or to other administrative penalties such as fines and warnings. ${ }^{8}$ Any product featuring alteration, adulteration, sophistication or falsifica-

\footnotetext{
7 The fraud triangle includes three elements: opportunity, motivation and rationalization. The first element refers to the ability to commit the fraud as fraudsters do not wish to be caught; the second element refers to incentives, which come from a financial pressure or need felt by the potential fraudster; while the third element involves the person in reconciling the fraudulent behavior with the commonly accepted notions of trust. In other words, risks of fraud are more likely perpetrated by individuals who are in a position that helps them to make fraud, coupled with feeling under pressure and having low moral standards (Cressey 1953).

8 Seizures refer to more serious infringements to the rules and norms (e.g. food adulteration that can have harmful effects) than, for example, mere administrative non-compliance not leading to seizure. This carries
} 
tion is identified as "irregular product", while the subset of irregular products that are withdrawn from the market is identified as "seized product". 9 Finally, the agent that commits fraud is called "irregular establishment".

However, the ICQRF dataset only partially mirrors the structure of the wine value chain as reported in Fig. 1 because of some limitations in the information provided. On the one hand, it is impossible to single out industrial wineries and farm wineries because no such information is available and no data are available on business dimensions. Similarly, no information about the different typologies of retailing, i.e. traditional retailers vs. modern distribution, is reported. Furthermore, because of the integration of several functions at packaging stage, all establishments performing storage, transportation, wholesaling, and bottling have been considered under bottlers-wholesalers. On the other hand, there are some firms providing services to wine-making firms that are inspected and it is worth to keep them separate from other actors. In short, we end up with a simplified structure of the wine value chain including the following actors: individual wineries (farm as well as industrial), cooperative wineries, bottlers-wholesalers, service providers, retailers, and Ho.Re.Ca.

Figure 3 shows how the ICQRF inspection activities have been distributed at different stages of the value chain over the period 2007-2015. The distribution of inspections reflects both the size of agents at different stages as well as the ICQRF expectations about the likelihood of making frauds. In fact, about two thirds of inspections are carried out at the level of processing. However, the bulk of these inspections targets individual wineries, while inspected cooperative wineries account only for a trivial $0.6 \%$ of the total. Retailing come second as proportion of inspections with about one fifth of total, and third come the bottlers-wholesalers with some $11 \%$ of total.

The highest share of irregularities is among individual wineries, accounting for more than three quarter of total irregularities, a proportion that is noticeably higher than that of inspections. This confirms the wine-processing phase as the most critical stage in terms of fraud opportunities (cf. Sect. 3.1). A share of irregularities largely in line with the inspection rate (11.5\% vs. $10.2 \%$, respectively) applies also to bottlers-wholesalers, with bottling and transportation showing a higher intensity of irregularities as compared to storage and wholesaling. Retailing and Ho.Re.Ca. show considerably lower shares of irregularities. Indeed, in most cases these agents are not responsible for the irregularities detected at their level that are traced back to the responsible agent upstream the value chain.

To shed light on the intensity of frauds along the value chain, we calculate various indicators at different stages (Fig. 4). The ratio of irregular establishments to inspected establishments is the highest among service providers (36\%) whose number of inspections do not exceed on average $2 \%$ of total inspections. The ratio ranges between 22 and $26 \%$ among cooperative wineries, individual wineries and bottlers-wholesalers. Retailers and Ho.Re.Ca. operators have both lower ratios (about 5\%). The distribution in terms of seizure value mirrors that of irregularities with individual wineries, bottlers-wholesalers and retailers accounting for almost total seizures.

Footnote 8 continued

important information for wine fraud analysis that we deem important to disclose to the interested reader. Therefore, we perform the analysis for both seized and irregular products.

9 As a result, seized products represent a lower bound in the estimate of food fraud, while irregular products detected by inspection activity represent its upper bound. 


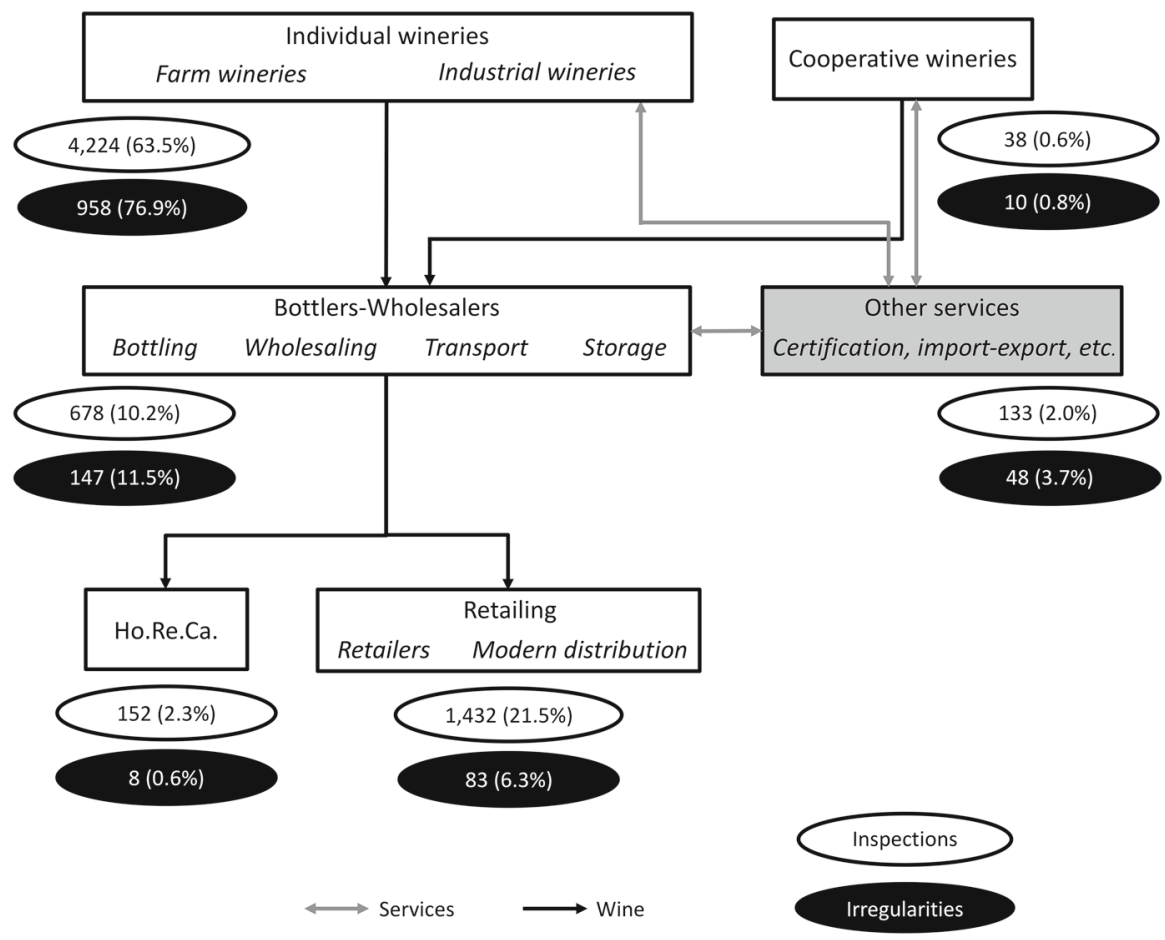

Fig. 3 Distribution of inspected and irregular establishments: numbers and proportions (yearly averages)

\section{Modelling the Impact of Wine Fraud in a SAM Framework}

\subsection{A Short Introduction to SAM}

A SAM is a comprehensive and disaggregated representation of the transactions within an economy in a matrix form. Each 'sector' of the economy (an industry, the market for a given commodity, the current account of a given institution and so on) is represented by a row/column couple recording the relative flows. As in a double-keeping accounting system the totals of inflows (row) and outflows (column) of each sector must balance.

The SAM model is a natural extension of the Input-Output model originally proposed by Leontief (1936) to analyze the technical interdependencies in the production system. SAMs are the empirical ground base of a wide spectrum of multi-sector empirical models (Round 2003) representing the structural interrelationships existing among production, income distribution, final consumption and capital formation.

The core of a SAM model is the matrix of direct expenditure coefficients, $\mathbf{B}$, that is the matrix of coefficients obtained dividing each single entry of the SAM by the corresponding column total. The size and the structure of the matrix $\mathbf{B}$ depends on the disaggregation of accounts in the original SAM as well as on the adopted 'closure'. As usual for single-country models, we assume the small economy hypothesis, consider- 


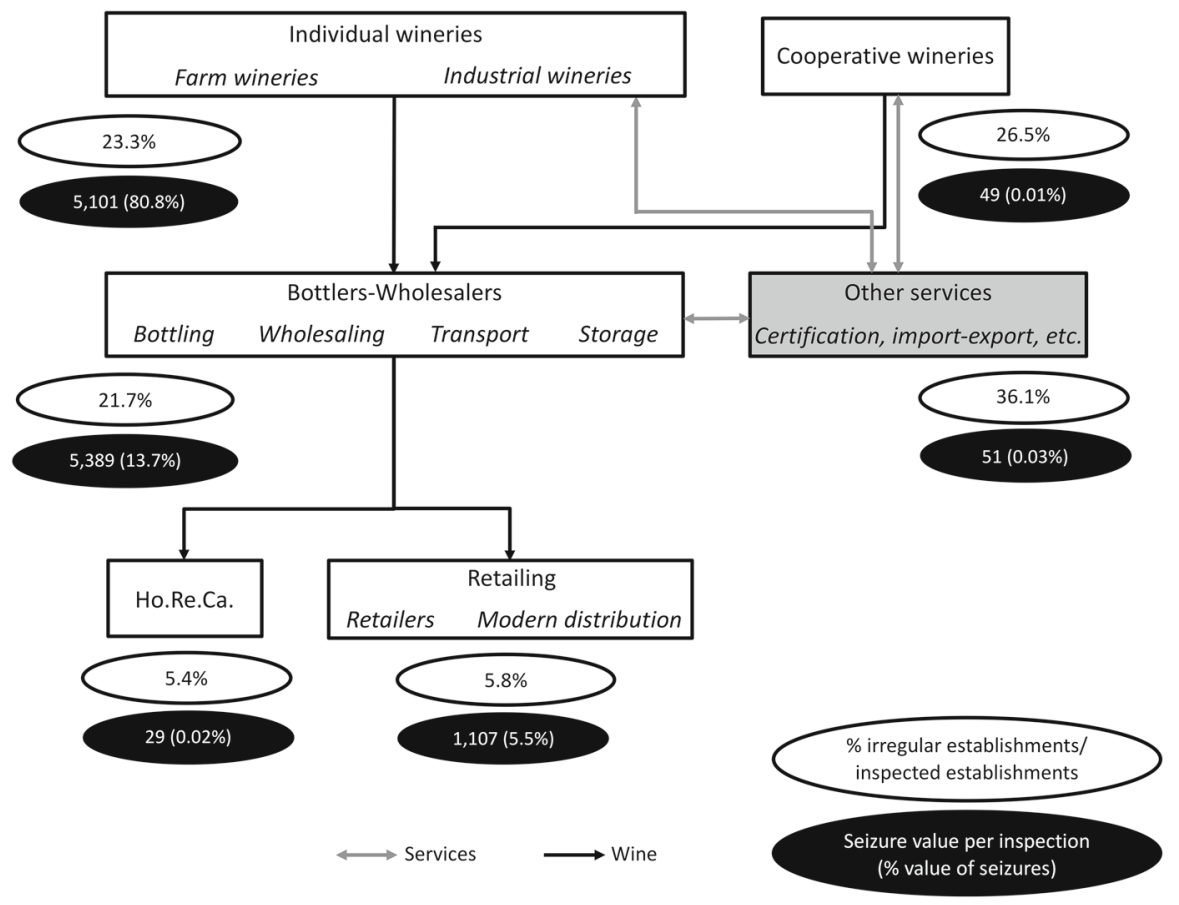

Fig. 4 Irregular establishment intensity, seizure value per inspection (euro) and percentage of seizure value on total seizure value along the wine value chain (yearly averages)

ing the Government and the exchanges with the rest of the world as exogenous. The process of capital formation is also assumed as exogenous, as our research question focuses on short-run (not dynamic) impacts. The resulting of matrix $\mathbf{B}$, including all endogenous accounts, is composed by the following blocks:

$$
\mathbf{B}=\left[\begin{array}{lllll}
0 & \mathbf{A} & 0 & \mathbf{F} & 0 \\
\mathbf{S} & 0 & 0 & 0 & 0 \\
0 & \mathbf{V} & 0 & 0 & 0 \\
0 & 0 & 0 & 0 & \mathbf{C} \\
0 & 0 & \mathbf{D} & 0 & \mathbf{T}
\end{array}\right]
$$

where $\mathbf{S}$ is the $(\mathrm{n} \times \mathrm{m})$ industry by commodity matrix showing the share of each commodity that is produced by each industry, $\mathbf{A}$ is the $(m \times n)$ matrix showing the value of inputs of each commodity per dollar worth of industry output, $\mathbf{V}$ is the $(\mathrm{v} \times$ n) matrix of coefficients of primary distribution of value added to production factors, D is the $(\mathrm{d} \times \mathrm{v})$ matrix of coefficients of primary income distribution from factors to institutions, $\mathbf{F}$ is the $(\mathrm{m} \times \mathrm{c})$ matrix of supply of commodities to consumption functions, $\mathbf{C}$ is the $(c \times d)$ matrix of final consumption expenditure coefficients of endogenous 
institutions, ${ }^{10}$ and $\mathbf{T}$ is the $(\mathrm{d} \times \mathrm{d})$ matrix of coefficients representing transactions among institutions. All other blocks are zero blocks of conformable dimensions.

A generic SAM linear model (Miller and Blair 2009) can be written in matrix form as follows:

$$
\mathbf{y}=\mathbf{B y}+\mathbf{x}
$$

where $\mathbf{y}$ is the vector of totals and $\mathbf{x}$ the vector of exogenous inflows towards endogenous accounts.

The solution of the system (1) maps the vector $\mathbf{x}$ of exogenous components to the vector $\mathbf{y}$ of totals of endogenous accounts through the matrix $\mathbf{M}$ of SAM multipliers:

$$
\mathbf{y}=(\mathbf{I}-\mathbf{B})^{-1} \mathbf{x}=\mathbf{M} \mathbf{x}
$$

where I is the identity matrix. Equation (2) shows that in SAM models the activation of the economy linearly depends on the magnitude of a vector of exogenous inflows towards endogenous accounts. This relationship holds also in difference:

$$
d \mathbf{y}=\mathbf{M} d \mathbf{x}
$$

where $d x$ is a vector of changes in exogenous injections, representing a given scenario to be assessed. The entries of matrix $\mathbf{M}$ can be interpreted as Leontevian-Keneysian multipliers, as the model is 'closed' towards consumptions and allows to account not only for the multiplier effects generated by inter-industry linkages but also for the additional impacts induced by income distribution and final expenditure. In this sense SAM models provide a more comprehensive account of multiplier effect than the input-output ones. ${ }^{11}$ Moreover, the inclusion of households as an endogenous sector allows to model how the distributive structure of the economy is likely to affect the impacts of exogenous shocks (Roland-Holst and Sancho 1992). These are the basic motivations to use a SAM rather than an input-output framework for our analysis.

\subsection{A SAM-Based Counterfactual Framework for the Analysis of Wine Fraud Impact}

The simulations carried out to assess the impact of frauds in the wine value chain refer to each of the two terms on the right-hand side in Eq. (3).

The first simulation uses the fraudulent wine output value, estimated according to the data provided by ICQRF (both seizures and other irregular products), as a vector of exogenous shocks, $d x$, to be injected into the model keeping $\mathbf{M}$ constant. We can interpret the dependence of wine demand on irregular productions as a measure of the vulnerability of the wine value chain to scandals/scares, especially considering that the demand for quality wines is largely driven by reputation. In this case, the larger

\footnotetext{
10 In the proposed model endogenous institutions ad households (10 groups by income deciles), firms (2 groups) and non-profit institutions serving households.

11 Stone (1985) provides an additive decomposition of multipliers showing that SAM-based multipliers encompass the corresponding input-output ones.
} 
the share of the final demand supplied by fraudulent products the higher the risk of a system disruption.

The second simulation adopts a counterfactual approach. Based on the structure of the interdependencies within the economy represented by the matrix $\mathbf{M}$ and using additional information from secondary sources and key informants, a new counterfactual matrix of SAM multipliers, $\mathbf{M}^{*}$, representing the Italian economy as if there were no frauds, can be derived. This makes possible to evaluate the impact of wine frauds, $\mathbf{c}$, by subtracting the level of activation that would be achieved should the farms/firms in the wine value chain be fully-compliant (that is not making frauds) from the actual level of activation of the Italian economy (as represented in the original SAM):

$$
\mathbf{c}=\left(\mathbf{M}-\mathbf{M}^{*}\right) \mathbf{x}=\mathbf{y}-\mathbf{y}^{*}
$$

where $\mathbf{x}$ is the vector of actual exogenous inflows towards all endogenous accounts, $\mathbf{y}$ is the vector of totals of actual endogenous accounts, and $\mathbf{y}^{*}$ is the vector of totals of endogenous accounts that would be observed should the production system be fully-compliant.

Developing a counterfactual in a SAM framework requires information on frauds that are by definition difficult to be disclosed by interested agents. Alternatively, sector experts and key informants could be approached to provide their best guess on the cost structure of the most common frauds perpetrated in the wine value chain. ${ }^{12}$ This is the procedure adopted in this study.

Formally the impact assessment can be summarized as follows. Let $\mathbf{A}_{\mathbf{f}}$ be the $(\mathrm{m} \times \mathrm{n})$ matrix of input coefficients of non-compliant (i.e. fraudulent) production activities. The $(n \times 1)$ vector $\mathbf{f}$ of total output of production activities is given by the sum of the $\mathbf{f}_{\mathbf{f}}$ vector of non-compliant production total values and the $\mathbf{f}_{\mathbf{r}}$ vector of compliant (i.e. regular) total output values. The use matrix $\mathbf{Z}_{\mathbf{f}}$ representing total intermediate consumptions (commodity by industry use matrix) for non-compliant production activities is computed via post-multiplication of diagonalized vector $\mathbf{f}_{\mathbf{f}}$ to the matrix $\mathbf{A}_{\mathbf{f}}$ :

$$
\mathbf{Z}_{f}=\widehat{\mathbf{A}_{\mathbf{f}}} \widehat{\mathbf{f}_{\mathbf{f}}}
$$

The use matrix for fully-compliant production activities can be obtained by the difference:

$$
\mathbf{z}_{\boldsymbol{r}}=\mathbf{Z}-\mathbf{z}_{\boldsymbol{f}}
$$

where $\mathbf{Z}$ is the use matrix in the original (i.e. actual) SAM. A matrix $\mathbf{A}_{\mathbf{r}}$, representing the expenditure coefficients for a production system including only fully-compliant production activities, can be estimated dividing the elements of $\mathbf{Z}_{\mathbf{r}}$ by the total value of regular products:

$$
\mathbf{A}_{\mathbf{r}}=\mathbf{Z}_{\boldsymbol{r}}\left({\widehat{\mathbf{f}-\mathbf{f}_{\mathbf{f}}}}^{-1}\right.
$$

12 Cf. Section 6.2.1 for details on how the key informant estimates have been elicited. 
Matrix $\mathbf{B}^{*}$, representing the fully-compliant (i.e. counterfactual) economy, is obtained substituting the modified matrix $\mathbf{A}_{\mathbf{r}}$ for the corresponding sub-matrix of direct input coefficients of production activities included in matrix $\mathbf{B}$ as resulting from the original SAM (i.e. based on actual data).

\section{The Building Blocks of Wine Fraud Simulations on the Italian Economy}

\subsection{Building a SAM of the Italian Economy for Food Value Chain Analysis}

Modelling the impact of wine fraud requires a SAM of the Italian economy appropriately disaggregated to single out the wine value chain as well as other relevant sector of the agri-food system. The input-output (I-O) table of the Italian economy for year 2009 estimated by the Italian Statistical Institute (ISTAT 2016), which includes accounts for 63 industries and for the corresponding products. However, in this table agriculture and food industry are represented by only one production account each and the corresponding two commodities, i.e. agricultural products and food products. Therefore, the agricultural sector was disaggregated to represent 8 different farming typologies according to the classification adopted at the European level within the Farm Accountancy Data Network (EU Regulation 2003/369), including the group of farms specialized in permanent crops such as vineyards. The account representing the Food Industry was disaggregated into 10 different of food processing activities, including wine-making, producing the corresponding 10 commodities, including wine. ${ }^{13}$ The disaggregation is fully consistent with the accounting rules defined within the European System of Accounts (Eurostat 2008). After the disaggregation the input-output table included 80 industries producing the corresponding 80 products. ${ }^{14}$

We then merged the disaggregated I-O supply and use tables with the SAM of the Italian economy estimated by the Tuscany Regional Institute for Economic Planning with reference to the same year (IRPET 2016). In fact, the original IRPET's SAM included a supply and use table based on the ISTAT 2009 table. The classification of industries and commodities in the IRPET table was fully consistent with that of the ISTAT table, though more aggregated ( 37 industries producing 54 commodities). Therefore, the inclusion of the disaggregated supply and use table in the IRPET's SAM was quite straightforward. Accounts for the other industries and commodities were reaggregated where necessary to harmonize with the classification adopted in the IRPET matrix. The new accounts for agriculture and food industry sub-sectors were balanced adjusting the value of depreciation in the disaggregation of value added, while the accounts for new food commodities were balanced adjusting variations in stocks. In the IRPET SAM, institutions purchase bundles of goods and services corresponding to 23 final consumption functions. Agriculture and food subsectors sell their products to

\footnotetext{
13 The disaggregation of industries and commodities accounts was based on the same microeconomic data used by ISTAT in the construction of the Input-Output table as well as on secondary data such as the Farm Accounting Data System public database (EU Commission 2019), the ISMEA 2003 use matrix of the Italian food system (ISMEA 2009) and the Eurostat structural business statistics database (Eurostat 2019).

14 Further details on the disaggregation procedures can be found in Rocchi et al. (2020).
} 
consumers throughout two functions (purchases of food and purchases of beverages). Therefore, the disaggregation of final consumption according to the new classification of commodities in the supply and use table was not necessary.

Eventually, the final SAM breakdown includes the following 183 accounts:

- 64 commodities,

- 54 industries,

- 12 accounts for primary income distribution,

- 23 final consumptions functions,

- 18 accounts for current income use by institutions (including 10 household groups according to deciles of equivalent per capita available income and 8 Government accounts),

- 9 accounts to represent capital formation, and

-3 accounts for flows with the rest of the world.

\subsection{Building the Vector of Wine Fraud Shocks}

An estimate of the monetary value of seized and irregular products is required to assess the impact of wine frauds on the Italian economy through SAM simulations. Specifically, an estimate of the monetary value of fraudulent wine at final consumption is needed as simulations are modeled as exogenous shocks on the final demand (cf. Sect. 4.1). Therefore, food fraud data need to be transformed as if they referred to products for final consumption, using proper technical coefficients to convert the fraudulent quantities detected at specific stages of the value chain in final consumption quantity equivalents. For example, if wine grapes are spotted as irregular, the quantity of grapes needs to be transformed into wine equivalent quantities using the technical conversion coefficients. Then the resulting quantities are multiplied by the consumer price of wine in order to get an estimate of the monetary value of irregular wine at final consumption.

ICQRF data shows there are three types of irregular/seized products: grapes, musts, and wines. We refer to technical data from the literature (Ribéreau-Gayonet et al. 2017) as well as Italian experts' judgments to retrieve realistic technical coefficients of conversion to transform the intermediate product quantities into final product equivalents, as follows: grapes to must: $0.70 \mathrm{~kg} / \mathrm{l}$; must to wine: 0.88 ; and grapes to wine: $0.616 \mathrm{~kg} / \mathrm{l}$.

In order to estimate an average representative price at final consumption we use the ICQRF dataset (ICQRF 2016) that includes detailed information on quantities and values of seized products at various levels of the value chain. The price is calculated as a weighted average of the quantities seized from production units that sell directly to consumers. However, since seizures have been enforced in different years, we deflate their values using the consumer price index with the base year 2009 (ISTAT 2016), that is the reference year of our SAM. The resulting average price to final consumption is 2.02 euro per liter of wine, expressed in euro 2009.

In order to make SAM simulations we need both value of seized and irregular wine, which represent a lower and upper bound of frauds, respectively. However, while in the case of seized products the ICQRF database reports both quantities and values, in the case of irregular products the database reports only quantities. Therefore, the 
estimation procedures to compute the final consumption equivalents of the two figures are different. In the case of seized product, in order to get a monetary estimate, it is good enough to multiply the quantity equivalent at final consumption of seized musts and grapes as well as wines times the average consumer price of wine: this will yield the sample-level estimates of the yearly average seizures. In the case of irregular products, we adopt a two-step procedure: first we calculate the ratios of the number of seized products to the irregular products from the ICQRF database, which averaged at $17.8 \%$ over the entire period of 2007-2015 for wine value chain, and then we divide the value of seized products by this rate to yield the value of irregular products at the sample level. ${ }^{15}$

The last step before getting the figures to be used in the SAM simulations is to expand these sample-level estimates to the population-level. In doing this, we use the ratio of the inspected establishments (sample) to the number of active establishment (population) as they result from the last Census on industry, commerce and services (ISTAT 2014). ${ }^{16}$ The resulting sampling ratio is $8.3 \%$. On average, if all establishments were inspected (and if all assumptions above would hold), the value of seizures expanded to the national population would be 470.7 million euro, while the value of irregular products would be 3,115.6 million euro, both values expressed in euro 2009. In SAM simulations we use these two estimates as lower and upper bounds of frauds in the wine supply chain, respectively.

\section{Results and Discussion}

\subsection{Vulnerability of the Italian Economy to Wine Frauds}

According to the social accounting matrix in 2009 the domestic food supply chain produced wine for a total value of 11.3 billion euro. Wine was supplied by production activities of different size and nature that could be classified into different industries within the SAM. The total value of output is shared between production activities classified under agriculture (47\%)—mostly small-medium specialized permanent crop farms carrying out the whole production process from the vineyard to the marketing of bottled wine (43\%) and other farms (4\%) - and the wine industry (50\%). Other manufacturing and service activities, including the other sectors of food industry, account for a tiny share of total output (about 3\%).

The average annual values of seized and irregular wine have been allocated among the different activities producing wine in the SAM, according to their own shares in total production of wine. The resulting vectors have been used as exogenous shocks in the SAM model to estimate the share of the Italian economy activated by the final demand for seized and irregular wine products. The estimated figures are not trivial. Even in the more conservative estimate, i.e. considering only seizures, the

\footnotetext{
15 This procedure rests on the implicit assumption that the composition of seizures is representative of the whole set of irregular products, which is indeed the case.

16 This implies the assumption that controls are random and the probability to find irregularities in the entire population is equal of probability to find them in companies subject to controls. We thank one of the anonymous referees for emphasizing this point.
} 
Table 2 Share of total economy activated by the final demand for irregular wine (euro 2009)
Table 3 Share of output value and employment activated by demand for irregular wine across agri-food sectors

\begin{tabular}{lrrrr}
\hline & Seized wine & \multicolumn{2}{c}{ Irregular wine } \\
\hline $\begin{array}{l}\text { Value of irregular wine (M } \\
\text { euro) }\end{array}$ & 471 & & 3116 & \\
$\begin{array}{l}\text { Share of total output (M euro) } \\
\text { Share of total employment } \\
\text { (000 labor unit) }\end{array}$ & 1390 & $0.05 \%$ & 9197 & $0.31 \%$ \\
$\begin{array}{l}\text { Share of value added (M euro) } \\
\text { Share of households' gross } \\
\text { income (M euro) }\end{array}$ & 613 & $0.05 \%$ & 4060 & $0.30 \%$ \\
\hline
\end{tabular}

\begin{tabular}{lcc}
\hline & Output (\%) & Labor units \\
\hline Specialized permanent crop farms & 11.51 & 55,855 \\
Other farms & 1.46 & 11,225 \\
Wine industry & 25.63 & 4599 \\
Other activities & 0.20 & 43,069 \\
\hline
\end{tabular}

fraudulent wine activities generate over 17 thousand labor units. Assuming that all irregular products were demanded by consumers, the share of total economy activated by irregular wine production would represent $0.31 \%$ of total output and almost $0.5 \%$ of total employment, that is almost 115 thousand full time labor units (Table 2).

The estimates are far more impressive when looking at the agri-food system breakdown (Table 3). Up to $11.5 \%$ of the output of specialized permanent crop farms and over $25 \%$ of wine industry would directly and/or indirectly depend on the final demand for irregular product. Should a food scandal/scare determine a drop in consumers' demand, the negative effect on production activities of these sectors may be large. This is extremely important for the Italian wine sector, a value chain where quality differentiation through immaterial attribute, primarily geographical origin of products, is at the core of its competitive advantages within the global markets. The potential negative impact is substantial, both within and outside the wine sector.

\subsection{Impact of Wine Frauds on the Italian Economy}

\subsubsection{Structure of Costs}

In order to build a counterfactual SAM representing a hypothetical fully-compliant wine sector, we estimated the $\mathbf{A}_{\mathbf{f}}$ matrix (cf. Sect. 4.2) using information provided by a panel of $15 \mathrm{key}$ informants who are experts in the wine value chain organization across the country, playing leading roles within control bodies (ICQRF and the Agro-food Unit of the Italian Forest Service), research institutions (Council for Agricultural Research and Analysis of Agricultural Economics), producers associations (wine consortia), and freelance professionals specialized in the wine industry. 
Table 4 Structure of wine production costs: SAM average coefficients and fraudulent activities (\% of the output value)

Wine industry
SAM coefficients (\%) $\quad$\begin{tabular}{l} 
Fraudulent wine activities \\
\cline { 2 - 2 }
\end{tabular}

\begin{tabular}{lrrr}
\hline $\begin{array}{l}\text { Intermediate } \\
\text { consumption }\end{array}$ & & & \\
Agricultural products & 18.30 & 9.10 & 3.70 \\
Wine & 5.80 & 2.90 & 1.20 \\
Electric power, natural & 3.60 & 3.60 & 0.70 \\
$\quad$ gas, water & & & \\
Chemical products & 3.10 & 3.10 & 0.60 \\
Non-metallic minerals & 2.50 & 2.50 & 0.50 \\
Financial services & 5.60 & 2.80 & 1.10 \\
Legal, professional and & 9.60 & 9.60 & 9.60 \\
$\quad$ administrative & & & \\
$\quad$ services & 35.10 & 35.10 & 7.00 \\
Other goods and & & & 1.60 \\
$\quad$ services & 8.10 & 8.10 & 74.00 \\
Wages & 8.30 & 23.20 & \\
Profits & & & \\
\hline
\end{tabular}

The key informants were asked to provide information aiming at: (i) modifying the wine average cost structures as reported in the original SAM (i.e. the cost structure including both regular and irregular wine production activities) to better represent the activities of different production units, and (ii) identifying the vector of costs representing the cost structure of an average non-compliant production unit according to the most common frauds in the wine value chain. ${ }^{17}$ Table 4 reports the results of this exercise, including the vector of direct expenditure coefficients for the wine industry as in the original SAM (first column) and those of the two most common frauds (last two columns), namely wine produced adopting irregular wine-making practices (such as the use of wood chips to provide flavors to young wine) and commercialization practices not complying with administrative rules on process documentation and quality certification.

We assume these coefficients are representative of the average structure of costs in wine production irrespective of the winery type, e.g. farm wineries vs. industrial

\footnotetext{
17 The elicitation of expert estimates entails the following steps: a) qualitatively describe the most frequent frauds in the production of wine; b) modify the wine average cost structures (i.e. the SAM cost structures) to better represent the production activities of different production units; c) further modify the vector of costs to better represent cost structure of an average non-compliant production unit. The expert estimates were averaged and the resulting vectors were sent them back for a double check before being used in building the counterfactual scenario. A sensitivity analysis was carried out replicating the counterfactual analysis according to different hypotheses on the structure of costs in irregular activities, respectively halving ("best" case) and doubling ("worst" case) the output to intermediate costs ratio, relative to the "reference" estimate based on the expert estimates, yielding a modest variation in the estimated impact (cf. Rocchi et al. (2020) for further details).
} 
Table 5 Aggregate impact of wine frauds on the Italian economy (euro 2009)

\begin{tabular}{lcrrrr}
\hline Impact on & \multicolumn{2}{l}{ Seized wine } & & & Irregular wine \\
\cline { 2 - 3 } & Absolute value & \% impact & & Absolute value & \% impact \\
\hline Total output (M euro) & $-10,588$ & 0.000 & & $-405,802$ & -0.014 \\
Total employment (labor units) & -359 & -0.001 & & -5723 & -0.024 \\
Value added (M euro) & 2399 & 0.000 & 5534 & 0.000 \\
Households' gross income (M euro) & -9352 & -0.001 & & $-119,331$ & -0.007 \\
\hline
\end{tabular}

and cooperative wineries. This assumption seems reasonable for two reasons. First, in the disaggregation of production accounts to build the SAM (Rocchi et al. 2020) each production unit is classified under a given industry according to a prevalence criterion in production. ${ }^{18}$ Second, wine processing, like other bio-based activities carried out at the farm level, is a process with limited economies of scale. Even though the production units belonging to the wine industry account (i.e. industrial and coop wineries) are likely larger than those belonging to the specialized permanent crops account (i.e. farm wineries), we can assume that the production cost structure is similar in both cases.

According to the experts most wine frauds are a combination of adopting irregular wine-making practices and not complying with administrative rules. Therefore, in calculating the matrix of multipliers for the counterfactual fraud-free wine sector, we assumed a cost structure of fraudulent activities equal to the average of the last two columns in Table 4.

\subsubsection{Aggregate Economy-Wide Impact}

The aggregate economic impacts of frauds in the wine value chain are summarized in Table 5. The level of activation of the economy decreases irrespective to the size frauds, i.e. assuming the value of the seized products only or the value of all irregular products. The loss of total output in the Italian economy due to wine frauds ranges between 11 and 406 million euro, causing an employment loss up to 6 thousand labor units. The results show an added value increase (between 2 and 6 million euro) along with an overall decrease in the economic activity level (losses in output and employment). Such a result represents a situation where frauds give raise to rents decreasing economic growth: the extra-profits from frauds are likely to not activate the circular flow as savings and incomes leak out towards exogenous accounts such as the public administration and the rest of the world. The potential loss in households' income ranges between 9 and 119 million euro.

\footnotetext{
18 This is true for both the wine industry account- the supply matrix included in the SAM shows that also these units supply a mix of different commodities, including agricultural products as well as other food products - and the farm wineries included in the specialized permanent crops farm categories — that include vineyard cultivation and other crops as well as wine-making.
} 
Table 6 Impact of wine frauds agri-food sectors (2009 euro; 000 labor units)

\begin{tabular}{|c|c|c|c|c|}
\hline \multirow[t]{2}{*}{ Agri-food sectors } & \multicolumn{2}{|l|}{ Seized wine } & \multicolumn{2}{|l|}{ Irregular wine } \\
\hline & $\%$ Total output & Labor units & $\%$ Total output & Labor units \\
\hline Meat and production of meat products & -0.01 & -3 & -0.05 & -28 \\
\hline $\begin{array}{l}\text { Processing and preserving of fish, } \\
\text { crustaceans and molluscs }\end{array}$ & -0.04 & -2 & -0.33 & -18 \\
\hline Production of olive oil & -0.02 & -1 & -0.15 & -5 \\
\hline Manufacture of other food products & -0.01 & -11 & -0.04 & -95 \\
\hline $\begin{array}{l}\text { Manufacture of processed vegetables and } \\
\text { fruits products }\end{array}$ & 0.00 & 0 & -0.04 & -11 \\
\hline Manufacture of dairy products & -0.02 & -11 & -0.17 & -85 \\
\hline $\begin{array}{l}\text { Manufacture of grain mill products, } \\
\text { starches and starch products }\end{array}$ & -0.03 & -2 & -0.19 & -18 \\
\hline Manufacture of prepared animal feed & -0.05 & -6 & -0.40 & -45 \\
\hline Production of wine & -0.08 & -15 & -0.69 & -142 \\
\hline Manufacture of other beverages & -0.01 & -3 & -0.09 & -27 \\
\hline Specialized field crops & -0.06 & -148 & -0.50 & -1305 \\
\hline Specialized permanent crops & -0.06 & -312 & -0.54 & -2845 \\
\hline Total agriculture & -0.06 & -709 & -0.51 & -6331 \\
\hline Total food industry & -0.02 & -55 & -0.13 & -475 \\
\hline
\end{tabular}

\subsubsection{Impact on the Agri-Food System}

The magnitude of impacts on agriculture and the food industry is larger than on the rest of the economy. The agricultural output shrinks because of wine frauds up to $0.51 \%$ while the output of the food industry would be reduced by $0.13 \%$ when considering irregular productions (Table 6). The impacts are differentiated among production activities within the agro-food system, ranging from $-0.05 \%$ of output in the meat industry to $-0.69 \%$ in the wine industry (estimates based on total irregular production). Due to the strong linkages between vineyard cultivation and wine production the impact on specialized permanent crop farms is significant $(0.54 \%$ of their potential output).

The largest loss of employment in absolute terms is recorded in agriculture (exceeding 6 thousand labor units in the upper bound estimate), $45 \%$ of which in the specialized permanent crop farms. Interestingly, the total employment loss in the agri-food system only is higher than the impact on employment in the whole economy ( -5723 full time labor units, cf. Table 5). This implies that the net effect on employment in the non-food economy is positive. Among sectors that benefit most from frauds are professional, scientific and technical activities, including legal and administrative services. This is a further element characterizing the rent effect generated by wine frauds. 


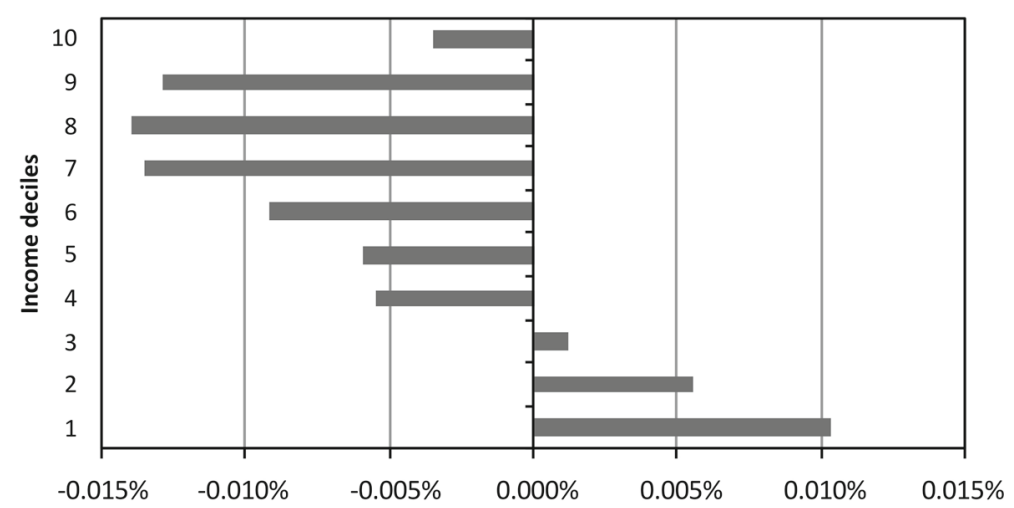

Fig. 5 Impact on households' gross income (\% values by income deciles)

\subsubsection{Distribution impact on household income}

Figure 5 shows the impact on household income distribution assuming a value of frauds equal to that of irregular products. The overall distribution of impacts is not regressive, showing positive impacts in the three lowest deciles and increasing negative impacts from the fourth decile upward. However, the relationship between frauds and income distribution is not linear, with the top decile of households showing a negligible negative effect. It is difficult to venture possible explanations for this pattern. In a SAM model the distribution of impacts on household incomes basically depends on the distribution of value added to production factor and on the structure of earnings of each family group. ${ }^{19}$ Overall, due to the difference in income levels between the two odds of distribution, the impact on inequality is likely to be small.

\section{Conclusion}

The contribution of this study to the scanty literature on the assessment of the economic impact of food frauds is twofold. From the methodological viewpoint, this paper proposes an approach to assess economy-wide impacts adopting a SAM analytical framework. Building a suitable disaggregated SAM makes possible to assess the share of the economy depending on the final demand supplied by irregular activities as well as to estimate the impact of wine fraud on the economy in a counterfactual framework. From the empirical viewpoint, our results show that the share of the Italian economy

\footnotetext{
19 Frauds modify the distribution of incomes among production factors (employed and self-employed labor, capital) and, as a result, affect the earnings of each family group according to the composition of their incomes. On one hand, the fraudulent wine production activities show a larger share of value added accruing to capital (likely to directly improve the relative position of higher deciles in income distribution). On the other hand, the induced impact of the distribution of income of fraudulent activities through final consumption is likely to relatively increase the demand for products produced by industries (mainly nonagricultural sectors) distributing a higher share of value added to employed labor (so improving the position of lower deciles in income distribution). The combined effect via direct, indirect and induced impacts results in the observed structure of impacts on households' incomes.
} 
that depends on the final demand for wine supplied by fraudulent production activities is not trivial. Wine frauds generate $0.5 \%$ of total employment and account for $0.31 \%$ of total output of the Italian economy. These estimates are much larger when looking at impact on the agri-food system: up to $11.5 \%$ of the output of specialized permanent crop farms and up to $25 \%$ of wine industry output may directly and/or indirectly depend on the final demand for irregular product.

We can interpret the heavy dependence of wine demand on irregular productions as a measure of the vulnerability of this sector to demand disruption should a scandal happen. This is of paramount importance for the Italian wine value chain where quality differentiation through immaterial attributes, primarily geographical origin, is the cornerstone of its competitive advantages in the markets. Paradoxically, it is the attempt to vertically differentiate wines that makes this value chain more vulnerable to the risk of fraud as fraudsters can exploit the complexity of implemented quality assurance systems. A direct policy implication would be simplifying administrative procedures required for quality differentiation and designing more effective and efficient controls as key components a food safety and quality assurance system. However, this might not be an easy task because, as shown by Anania and Nisticò (2004), the political economy of regulations for credence goods allows for a converging interest by the producers of high-quality goods and producers of low-quality goods in producing a political compromise that results in a regulation of little credibility and low effectiveness. $^{20}$

The SAM-based counterfactual analysis of the impact of wine frauds on the Italian economy shows that the loss of total output can be as high as 406 million euro per year (2009 value) considering the total value of irregular products. Significantly, the results show a slightly positive increase of value added along with a contraction of the activity level (losses in output and employment). We interpret such a result as the presence of fraud rents: the extra-profits from frauds do not activate the national economy as they partially leak out towards exogenous accounts such as the public administration and the rest of the world. In terms of employment, frauds in the value chain imply a loss of more 6.8 thousand labor units, mostly in the agriculture sector. Interestingly, the employment loss in the agri-food systems is larger than the employment loss in the whole economy. This implies that the net effect on employment in non-agricultural production sectors is positive, as it is specifically the case for legal and administrative services. This is an evidence that frauds other than wine sophistication are mostly paper frauds, due to non-compliance with production codes, incorrect DOP/IGP labeling, incorrect administrative rules on process documentation and quality certification, etc. We argue this as a further element supporting the rent-seeking nature of most wine frauds.

The overall conclusion emerging from the counterfactual analysis is that frauds in the wine value chain are not only a source of unfair competition to regular production activities, but also have an overall contractionary impact on the whole economy due to their character of directly unproductive rent-seeking activities (Krueger 1974; Bhagwati 1982). The policy implication is that more effective tools to combat food

\footnotetext{
20 The theoretical results by Anania and Nisticò (2004) could help in explaining the low effectiveness of existing regulations in the case of geographical indications.
} 
frauds are not only measures to increase the wine sector competitiveness in the global markets, but they are also effective pro-growth policies that are likely to determine positive impacts on employment in the short-run.

The value chain analysis shows that most irregularities (95\%) are made by only three agents, i.e. individual wineries, bottlers-wholesalers and retailers, who also account for almost all seizure value (99\%). Significantly, cooperative wineries are much less affected by frauds. The striking difference between individual and cooperative wineries may depend on lower fraud opportunities of the latter as compared to the former or to higher responsiveness to fines and loss of reputation of larger companies. This evidence resonates Parker's (2006) argument about a more difficult compliance in small production units because of a combination of limited liability ${ }^{21}$ and lower probability of being detected by control agencies, leading to a "deterrence trap". In order to improve monitoring efficiency, ICQRF may consider to pay more attention to individual wineries, especially those integrating different stages such as wine processing, bottling and distribution. In fact, production units involving several stages of production have a higher payoff in not-complying because the more complex the production process the more difficult to be detected, while expected gain from fraud increases since integrating various stages of production the value addition increases.

This study proves that making an overall assessment of the economic impact of frauds in a given value chain can be carried in a counterfactual framework using an appropriately disaggregated SAM. However, the accuracy of the estimates has been limited by the lack of data on counterfeiting of Italian wine abroad (i.e. the socalled "Italian sounding") and the lack of data on imported counterfeited intermediate products. While the impact of the former is likely to be trivial for a product such as wine, the latter could be of some importance. In both cases, however, should data on these illegal activities be available they could be easily included in the proposed framework through a change in the vector of the exogenous injections.

\begin{abstract}
Acknowledgements The authors would like to thank the staff and management of the Central Inspectorate for Agri-Food Quality Protection and Fraud Repression (Ispettorato Centrale per la Qualità e la Repressioni delle Frodi, ICQRF), namely Stefano Vaccari (ICQRF Director), Luca Veglia (Head of Risk Analysis Office), and Placido Iudicello (Data Manager), for providing primary data on seizures and irregularities as well as providing feedbacks on the research preliminary results. Important contributions were also provided by Amedeo De Franceschi, Head of the Nucleo Agroalimentare e Forestale del Corpo Forestale dello Stato (Agro-food Unit of the Italian Forest Service), providing data and discussing the most important fraud modalities in the wine value chain. The authors would like to thank also Francesco De Filippis and Dario Parenti, freelance value chain consultants, for discussing issues about wine frauds and providing background information/data to estimate the technical coefficients for converting intermediate products into final product. The authors wish to thank the Tuscany Institute for Economic Planning of (Istituto Regionale per la Programmazione Economic adella Toscana - IRPET) for providing the base 2009 national SAM for research purposes. Special thanks also to the Institute of International Education/Scholar Rescue Fund (IIE-SRF) for supporting Ahmad Sadiddin, a Syrian refugee scholar, while he was working on this topic as a post-doc research fellow at the University of Florence in 2015-2016.
\end{abstract}

Funding Open access funding provided by Università degli Studi di Firenze within the CRUI-CARE Agreement.

\footnotetext{
21 Limited liability happens whenever the maximum effective fine that can be imposed on any organization is bounded by the organization's capacity to pay the fine (i.e. its wealth).
} 
Open Access This article is licensed under a Creative Commons Attribution 4.0 International License, which permits use, sharing, adaptation, distribution and reproduction in any medium or format, as long as you give appropriate credit to the original author(s) and the source, provide a link to the Creative Commons licence, and indicate if changes were made. The images or other third party material in this article are included in the article's Creative Commons licence, unless indicated otherwise in a credit line to the material. If material is not included in the article's Creative Commons licence and your intended use is not permitted by statutory regulation or exceeds the permitted use, you will need to obtain permission directly from the copyright holder. To view a copy of this licence, visit http://creativecommons.org/licenses/by/4.0/.

\section{References}

Anania G, Nisticò R (2004) Public regulation as a substitute for trust in quality food markets: what if the trust substitute cannot be fully trusted? J Inst Theor Econ (JITE)/Zeitschrift für die gesamte Staatswissenschaft 160(4):681-701

Avery J (2014) Fighting Food Fraud. Briefing Report, European Parliamentary Research Service, Members' Research Service 130679REV1. European Parliament, Brussels. http://www.europarl.europa. eu/RegData/bibliotheque/briefing/2014/130679/LDM_BRI(2014)130679_REV1_EN.pdf.

Bhagwati J (1982) Directly unproductive, profit-seeking (DUP) activities. J Political Econ 90(October):988-1002

CENSIS-Centro Studi Investimenti Sociali (2012) Counterfeiting: Scope, Characteristics and In-depth Analysis of the Phenomenon. CENSIS-Ministero dello Sviluppo Economico, Rome. http://www.uibm. gov.it/attachments/Counterfeiting_Scope,\%20characteristics\%20and\%20analyses.pdf

Cressey DR (1953) Other people's money. Patterson Smith, Montclair

De Franceschi A (2016) The most common frauds in the Italian wine value chain. Personal communication, Head of the Agro-food Unit. Italian Forest Service, Roma

EU Commission (2019) Farm Accountancy Data Network, Public Database. Agriculture and Rural Development. https://ec.europa.eu/agriculture/rica/database/database_en.cfm. Accessed 15 July 2019

Eurostat (2008) Eurostat manual of supply, use and input-output tables. Office for Official Publications of the European Communities, Luxembourg

Eurostat (2019) Eurostat Structural Business Statistics and Global Business Statistics Database. https://ec. europa.eu/eurostat/web/structural-business-statistics/data/database. Accessed 15 July 2019

Fabbri B (2013) I controlli sui prodotti vitivinicoli a denominazione di origine: il quadro di sintesi. In: Menghini S, Fabbri B (eds) Qualità e tracciabilità della filiera dei vini a denominazione per la tutela del consumatore e la competitività delle imprese. Franco Angeli, Milano

Federalimentare (2016) La posizione dell'Industria Alimentare Italiana rispetto alla contraffazione ed al fenomeno dell'Italian Sounding. Federalimentare, Roma. http://www.federalimentare.it/new201 6/AreeOperative/Promozione_Internazionalizzazione/ItalianSounding.pdf

Federalimentare (2019a) Le cifre di base dell'industria alimentare italiana. Cibus-Salone Internazionale dell'Alimentazione, Parma. https://www.cibus.it/wp-content/uploads/2019/02/Cifre-di-base-2013-1 4-15-16-17-2018.pdf

Federalimentare (2019b) L'Italian sounding nell'industria alimentare. Consuntivi e Proiezioni (stime miliardi di euro). Cibus-Salone Internazionale dell'Alimentazione, Parma. https://www.cibus.it/wpcontent/uploads/2019/02/ITALIAN-SOUNDING-Consuntivi-e-proiezioni.pdf

FEDERDOC — Confederazione Nazionale dei Consorzi Volontari per la Tutela delle Denominazioni dei Vini Italiani (2019) I vini italiani a denominazione d'origine 2018. FEDERDOC-MIPAAF, Roma. https://www.federdoc.com/new/wp-content/uploads/2018/05/brochure-2018.pdf

Iaderosa A (2013) Il ruolo dell'Ispettorato centrale della tutela della qualità e della repressione frodi nei prodotti agro-alimentari (ICQRF). In: Menghini S, Fabbri B (eds) Qualità e tracciabilità della filiera dei vini a denominazione per la tutela del consumatore e la competitività delle imprese. Franco Angeli, Milano

ICQRF-Ispettorato Centrale per la Qualità e la Repressioni delle Frodi (2016) Datasets of central inspectorate for quality protection and fraud repression in agro-food products. ICQRF, Roma

ICQRF - Ispettorato Centrale per la Qualità e la Repressioni delle Frodi (2019) ICQRF Report 2018. ICQRF, Roma. https://www.politicheagricole.it/flex/cm/pages/ServeBLOB.php/L/IT/IDPagina/13602\#main 
INEA-Istituto Nazionale di Economia Agraria (2011) Analisi delle filiere vitivinicola, oleicola e lattierocasearia a supporto della programmazione dell'attività di controllo dell'ICQRF. Istituto Nazionale di Economia Agraria, Roma

IRPET - Istituto Regionale per la Programmazione Economica della Toscana (2016) Multiregional SAM of the Italian Economy, year 2009. IRPET, Firenze. http://www.irpet.it/matrici-input-output-e-samregionali?lang=en. Accessed 9 Mar 2016

ISMEA-Istituto di Servizi per il Mercato Agricolo Alimentare (2009) La tavola delle risorse e degli impieghi del sistema agroalimentare italiano 2003. Istituto di Servizi per il Mercato Agricolo Alimentare, Roma

ISMEA-Istituto di Servizi per il Mercato Agricolo Alimentare (2019a). La bilancia commerciale agroalimentare dell'Italia nel 2018. ISMEA, Roma. http://www.ismeamercati.it/flex/cm/pages/ServeBLOB. php/L/IT/IDPagina/9319

ISMEA-Istituto di Servizi per il Mercato Agricolo Alimentare (2019b) Scheda di settore: vino. ISMEA, Roma. http://www.ismeamercati.it/flex/cm/pages/ServeBLOB.php/L/IT/IDPagina/3525\#MenuV

ISTAT_-Istituto Nazionale di Statistica (2014) Industry and Services Census of 2011. ISTAT, Roma. http:// dati-censimentoindustriaeservizi.istat.it. Accessed 8 June 2016

ISTAT-Istituto Nazionale di Statistica (2016) Consumer Price Index with reference years 2009 and 2011. ISTAT, Roma. https://www.istat.it/en/archive/CPIon. Accessed 16 June2016

ISTAT-Istituto Nazionale di Statistica (2019a) I.Stat-Conti della branca agricoltura, silvicoltura e pesca. ISTAT, Roma. http://dati.istat.it/Index.aspx?DataSetCode=DCCN_VAAGSIPET. Accessed 22 Aug 2019

ISTAT-Istituto Nazionale di Statistica (2019b) I.Stat-Occupati per branca di attività. ISTAT, Roma. http:// dati.istat.it/Index.aspx?DataSetCode=DCCN_VAAGSIPET. Accessed 22 Aug 2019

Krueger A (1974) The political economy of the rent-seeking society. Am Econ Rev 64(3):291-303

Leontief W (1936) Quantitative input-output relations in the economic system of the United States. Rev Econ Stat 18:105-125

Malorgio G, Pomarici E, Sardone R, Scardera A, Tosco D (2011) La catena del valore nella filiera vitivinicola. Agriregionieuropa 7(27):14-19

Manning L, Soon JM (2016) Food safety, food fraud, and food defense: a fast evolving literature. J Food Sci 81(4):R823-R834

Mazzarino S, Corsi A (2014) I flussi dell'uva verso la vinificazione: un'analisi comparata per regioni e macroaree. Working Paper Series, Dipartimento Economia e Statistica Cognetti de Martiis, Università degli Studi di Torino, Turin

Menghini S, Fabbri B (eds) (2013) Qualità e tracciabilità della filiera dei vini a denominazione per la tutela del consumatore e la competitività delle imprese. Franco Angeli, Milano

Miller RA, Blair PD (2009) Input-output analysis. Foundations and extensions. Cambridge University Press, New York

MIPAAF-Ministero per le Politiche Agricole, Alimentari e Forestali (2017) Osservatorio della cooperazione agricola italiana. Rapporto 2017. MIPAAF, Roma

Parker C (2006) The "compliance" trap: the moral message in responsive regulatory enforcement. Law Soc Rev 40(3):591-622

Ribéreau-Gayon P, Glories Y, Maujean A, Dubourdieu D (2017) Trattato di enologia, 4a edn. Edagricole, Bologna

Rocchi B, Romano D, Sadiddin A, Stefani G (2020) Assessing the economy-wide impact of food fraud: a SAM-based counterfactual approach. Agribusiness 36(2):167-191

Roland-Holst DW, Sancho F (1992) Relative income determination in the United States: a social accounting perspective. Rev Income Wealth 38:311-327

Rosellini D, Fabbri B (2013) La tracciabilità di filiera nei vini DOC e DOCG. Il piano dei controlli. In: Menghini S, Fabbri B (eds) Qualità e tracciabilità della filiera dei vini a denominazione per la tutela del consumatore e la competitività delle imprese. Franco Angeli, Milano

Round J (2003) Constructing SAMs for development policy analysis: lessons learned and challenges ahead. Econ Syst Res 15(2):161-183

Spink J, Moyer DC (2011) Defining the public health threat of food fraud. J Food Sci 76(9):157-163

Spink J, Moyer DC, Park HH, Heinonen JA (2013) Defining the types of counterfeiting, counterfeiters, and offender organizations. Crime Sci 2(8):1-10

Stone R (1985) The disaggregation of the household sector in the national accounts. In: Pyatt G, Round JI (eds) Social accounting matrices. A basis for planning. The World Bank, Washington, pp 145-185 
Publisher's Note Springer Nature remains neutral with regard to jurisdictional claims in published maps and institutional affiliations.

\section{Affiliations}

\section{Donato Romano ${ }^{1}(\mathbb{D})$ Benedetto Rocchi ${ }^{1} \cdot$ Ahmad Sadiddin $^{2}$.}

\section{Gianluca Stefani ${ }^{1}$ - Raffaella Zucaro ${ }^{3}$. Veronica Manganiello ${ }^{3}$}

$凶 \quad$ Donato Romano

donato.romano@unifi.it

1 Dipartimento di Scienze per l'Economia e l'Impresa (DISEI), Università degli Studi di Firenze, Via delle Pandette, 9, 50127 Florence, Italy

2 Food and Agricultural Organization of the United Nations, Viale delle Terme di Caracalla, 00100 Rome, Italy

3 Consiglio per la Ricerca in Agricoltura e l'Analisi dell'Economia Agraria, Centro Politiche e Bioeconomia (CREA-PB), Via Po, 14, 00198 Rome, Italy 